\title{
International Labor Mobility, Unemployment Impact to Economic Growth
}

\author{
Nadia Faisal, Umair Ali Ansari, Muhammad Hussnain, Sayyed Khawar Abbas
}

\begin{abstract}
International labor mobility and unemployment are two faces of the coins and they comprehensively affect the economic growth so that this study deals with the analysis to check the effect of international labor mobility and unemployment at economic growth. 1992 to 2017 data is collected with 5 years lap from United States, Australia, Canada, Switzerland, Germany, France, and the United Kingdom. Purposive and Convenient sampling technique used for data collection. The implication for the countries policy makers and departments related to immigration. Study adhere to the limitations of sample size which can be increased for further study.

Key Words: Labor Migrations, Unemployment, Economic Growth, Developed Countries
\end{abstract}

\section{INTRODUCTION}

The global community has to be certain about where the true crisis is. The large part of the world's refugees is not, actually, storming European shores, Katja states. On each side of the border, millions of jobs are determined by the company ties between both nations. Individuals are worried about the short-term effect of large inflows of migrants, and refugees particularly, and lots of them feel that migration is threatening their economic, social and personal security. One-in-five foreign migrants dwell in the United States. Migration is a critical quality of a more interconnected world.

The Gulf States generally speaking have the maximum proportion of immigrants ( $\mathrm{Ng}$, Zaghloul, Ali, \& Harrison, 2011). The hottest statistical estimates of international migrants created by the UN can provide help. The very first region that I want to look at is the Northeastern Seashore.

The majority of them are Colombian. These days, the companies they founded have come to be the backbone of the international technology market. Financial and societal remittances are an important element of the GCM discussions.

The society's most of us live in are distributing the advantages of globalization and financial processes extraordinarily unfairly. International citizenship for a sign of the world interdependence and disconnectedness have an effect in meeting the challenge of migration flow. The impacts of large-scale depopulation could be rather dire.

Revised Manuscript Received on July 22, 2019.

Nadia Faisal, University of Education Lahore, Township Campus

Umair Ali Ansari, Hailey College of Commerce, University of the Punjab Muhammad Hussnain, Institute of Management Sciences, Bahauddin Zakariya University

Sayyed Khawar Abbas, Hailey College of Commerce, University of the Punjab
If you wish to excel as a worldwide mobility specialist, then you have to master global mobility economics. A number of jobs in the upcoming world of work is going to be generated in areas that don't yet exist. Often wages of native-born workers gain from the existence of immigrants to the extent which their skills are complementary to one another.

There continue to be exemptions on some health care grounds, however, along with accommodations for applicants who require a home-based fingerprint appointment. Far too frequently, the international mobility challenge for employees is exacerbated by an absence of support from employers. New technology has to be adopted and workers have to be upskilled to handle them.

There are not any financial miracles. Every case will differ. The matter of immigration is a traditional illustration of folks invoking the notion of human rights when they actually mean something different.

There are a lot of explanations for why climate refugee status doesn't make sense for those who might have to move. The government maintains it's a temporary measure until more bed space is available. There are more people that are unemployed that leave the nation, making sense as they try to look for labor opportunities elsewhere.

Suicide rates have risen also. Taxpayers have little to fret about in regard to the expenses related to migration. One reason we should want increased birth rates is so that we may take in more immigrants.

Over the last three decades, cities have grown at an unprecedented speed, adding a mean of 65 million people annually. If anything, higher-tariff nations generally have larger trade deficits. Likewise, top pork exporters including Germany could reap financial rewards as an immediate outcome of the spat.

Done right, there's much for everybody to gain from global trade. Structural factors like technology and globalization will most likely prevent any sharp increase in inflation. In general, labour market evolution differs across countries, suggesting that country-specific aspects play a very important function.

What's more, the amount of resettlement places is diminishing, together with funding that even at its greatest levels was not sufficient to meet the requirements of refugees. What's more, when immigrants arrive in, it isn't merely the company that benefits, but they have a multiplier effect on the neighborhood economy, Peri explained. The focus of policymakers on highly skilled migration will probably continue, and might even rise in the coming decades.

Published By:

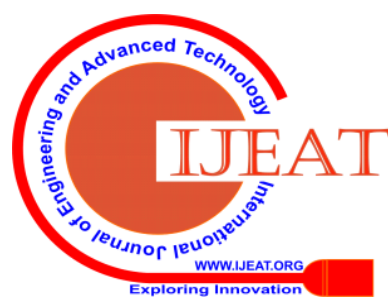




\section{International Labor Mobility, Unemployment Impact to Economic Growth}

\section{LITERATURE REVIEW}

The liaison of economic development has become debatable topic nowadays and roots are from early literature (Smith, 1776)(Hamilton, 1781). (Bagehot, 1873)(Wicksell, 1898) . Labor mobility can be caused due to many reasons and it can show many different effects. It's very general and may be referring to any of numerous mouse behaviors. Based on the present country situations, the next policy recommendations emerge. When specific examples are provided, they're not designed to be an all-inclusive list. Chinese immigrants have become the third largest part of immigrants after Mexicans and Indians in America (Zong \& Batalova, 2017).

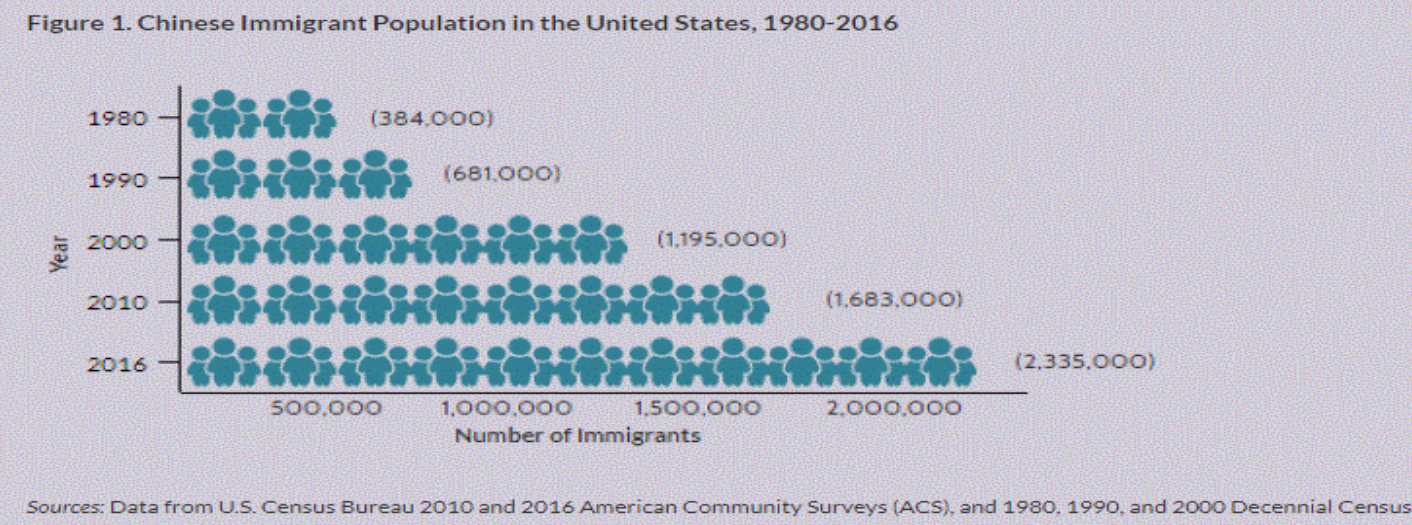

There are a lot of factors which are preventing great labor mobility (Obstfeld \& Taylor, 1997) that is the ability for job searchers to move from a region where they can't find to work to a different area where work is available. Job mobility is still quite low. In the very first location, it is typically costly and inconvenient for employees to move from 1 locality to another, and they might lose working time in making any change of jobs. The trend today differs. Customers who use Uber app don't need to stand at the face of the path to catch a ride. You might resort to this form of introduction when you're attempting to fill space as it's a familiar, comfortable format. My challenge to you is to get started paying attention to your ideas and become mindful of whenever you're making assumptions and get into action and ask the ideal questions. Furthermore, the lack of an effect could be very telling in many scenarios. You never receive a second chance to create a first impression. \At length, you should have effective hiring processes staffed by people who know what they're doing. The point is that consumers will be more informed in their decisions to prevent objectionable content. Also, there's no conclusive evidence to demonstrate that Uber has singlehandedly affected the conventional taxi market. It has created a challenge for labor mobility too. It's characterized by the debut of the pointed arch. The second portion of the token is the payload, which has the claims. The openness, global reach, and absence of physical clues that are inherent qualities of e-commerce also allow it to be vulnerable to fraud and therefore increase certain costs for e-commerce merchants as compared to conventional stores.
Some nations have chosen to raise taxes, while some have lowered tax rates to entice individuals and companies in an attempt to boost the domestic economy. Civilians need to be able to seek advice from their diplomas and handle the visibility of individual diplomas. Over the very long arc of U.S. history wages have fluctuated together with the economy.Enlarging the market is going to have a positive impact on jobs. Additionally, e-commerce is quite good at reducing the expenses of attracting new clients, because advertising is typically less expensive than for different media and more targeted. This is only one of the countless examples of corporations, and individuals, finding ways to be successful in tax evasion.Potentially it's because the incidence of rather long duration jobs has also fallen. Consistent with lower headship prices, young adults today are not as likely to be homeowners as young adults of earlier generations. The population boom in this nation, which is usually reckoned as among the nation's predicaments as the surging amount of Filipinos is indirectly proportional to the employment opportunities readily available, ought to be taken advantage of by encouraging the surplus of people to come up with employment and enhance the rural farmlands States and civil society actors should make sure that the Global Compacts enshrine the total suite of human rights protections or derogate. Remittances have a direct effect on families along with an indirect impact on the nation. Missionaries were an important component in promoting economic shift.

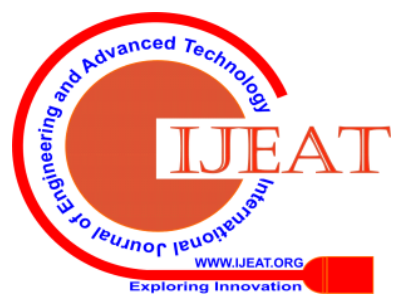


Therefore, a JWT typically resembles the next. The business recognizes the value of reaching out a bigger amount of people through the internet, which is evident in its strong online presence. Even for important crucial positions, some businesses don't take the opportunity to determine what the job requires.It's absolutely amazing to me the range of managers and businesses that begin a work search with a sketchy or no idea about what they're searching for in a candidate. It's shown that LFNs can be helpful in identifying firms with higher growth potential. Next steps are to involve the vital stakeholders at European level and get started developing a consortium.So long as a considerable majority of
American adults feel that their children won't live in addition to they did, our politics will stay bitter and divisive (Summers 2017). You have to determine the human abilities and traits necessary to be successful in the job. It has to be interpreted to mean equal access to all students for all probable positions.

When writing, you have to place your ideas in context but that context doesn't generally must be as big as the entire galaxy! It can also explain certain elements which are important to the essay if explanations aren't part of the principal text. You will have to revise your paper to be certain that the introduction, all the evidence, and the conclusion reflect the argument you intend.

\section{Number of migrants in Middle East more than doubles between 2005 and 2015}

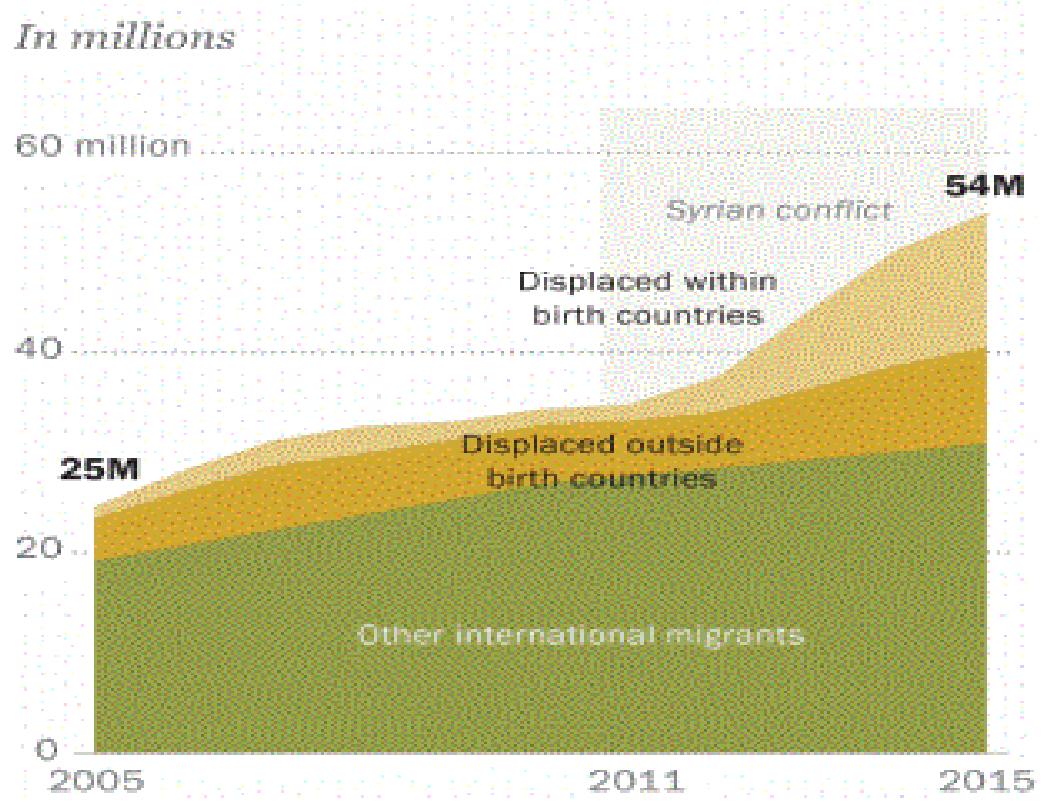

Pew research center researcher Connor (2016) conducted the research and shows that how migrates in Middle East turn doubled the Middle East population. The study discussed how population increased by $120 \%$, more precisely it includes sub proportions Africa (91\% growth), Latin America and the Caribbean (77\%) and the Asia-Pacific region (26\%). This could easily describe how much impact countries got from labor mobility.

Hence the greater quantity of men and women demand a limited number of products, which results in a price hike. Personal impediments consist of physical place and physical and mental ability.

At precisely the same time, unrestricted labor can depress wages in some specific industries and make unemployment (Friedberg \& Hunt, 1995). Meanwhile, a number of the lowest unemployment rates chance to be in rather undesirable regions to live, like the upper-Midwest. Voluntary unemployment is understood to be a circumstance when workers decide not to work at the present equilibrium wage rate. It also has been seen that The China-Australia Free Trade Agreement (ChAFTA) has boosted the economic growth and has created a lot of jobs in 2015. The evidence of provisional conjunction in China's growth has been observed due to labor mobility, even labor alteration do have a negative impact at market growth (Cai, Wang, \& Du, 2002).

There are a lot of forms of unemployment, defined with regard to cause and severity. He's got to consider noneconomic along with economic factors and to look at the long-run in addition to the immediate prospect. This is no little deal for a little country already suffering from internal political and financial difficulties. Much enjoy the Hoover high-wage policy (though not as dramatic), among the impacts of the housing debacle has been to lower labor mobility.

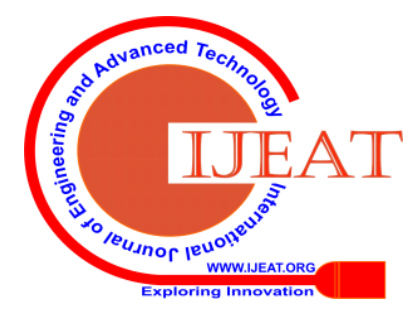




\section{International Labor Mobility, Unemployment Impact to Economic Growth}

Unless employers demand more workers, a rise in labor supply could result in a glut in labor. A house is additionally a tangible asset that gives owners with borrowing power and allows our citizens to construct wealth which they can pass on to their kids and grandchildren.

This is very intense for smaller nations that are highly dependent upon the tourism industry as a significant supply of their GDP and employment. Professor Oswald pointed to a few of the data as far back as 1996, saying that in Europe together with the United States of America a greater proportion of homeownership seemed to be connected with a high degree of unemployment. Between countries, it's accomplished through treaties or financial agreements.

Economic development perspective is strong and it's developed by several different factors (Cihak, Demirguc-Kunt, Feyen, \& Levine, 2013)(Svirydzenka, 2016).

\section{SIGNIFICANCE OF THE STUDY}

The study will explore the important impact of labor mobility upon economic growth moreover it will also discuss the relationship of labor mobility on unemployment. Literature is almost silent to the second context so this study will come up with multiple useful implications.

Objectives and Research Questions

In the light of the above literature following are the research objective and question of the current study

$\checkmark \quad$ To explore the impact of Labor Mobility at countries economic development

$\checkmark$ To explore the impact of labor mobility at unemployment of country

\section{METHODOLOGY}

Study contains the times series data and analysis is going to run is regression analysis to check the model effectiveness and sampling it is using is a mixture of purposive and convenient sampling. The study will explore the very sensitive matter of employment which is directly related to the economic growth of a country that why it is following a very intrusive amount of posture to explain. Following are the key step to conduct the study. Data was taken by selective counties from 1992 to 2017 after each five years gap. Because of unavailability of data in sense of immigration. United States, Australia, Canada, Switzerland, Germany, France, and the United Kingdom are the countries which come under the study.

\section{MODEL}

Economic Development $=\mathrm{a}+\mathrm{b} 1$ Labor Migration $+\mathrm{b} 2$ unemployment $+\mathrm{e}$

The model contains the dependent variable of economic development it will explain the economic growth changing with respect to independent variables which are labor migration and unemployment. It is supposed that labor migration could have a positive and negative relationship with economic development whereas unemployment could have a negative relationship with economic development.

\section{RESULTS}

During analysis due to a shortage of time and data study selected the 5 countries which normally observe a huge amount of labor mobility and performing very well for many years. Following table shows the regression analysis.

\begin{tabular}{|c|c|c|c|c|c|}
\hline ed & Std. Err. & $\mathrm{P}>|\mathrm{t}|$ & {$[95 \%$} & onf. Interva & \\
\hline \multicolumn{6}{|c|}{ - } \\
\hline mo_n & 24717.94 & 0.37 & 0.716 & -111599.4 & 161035.3 \\
\hline _cons & 745151.5 & 3.98 & 0.000 & 366415.7 & 1123887 \\
\hline
\end{tabular}

$\mathrm{R}$ Square was 0.0003 and above table shows the regression analysis results. It can easily watch that apparent mobility do not impact properly to countries economic growth. It doesn't have any relation to it.
The following table shows the correlation analysis results

\begin{tabular}{l} 
| ed mo_n \\
\hline------------+----------------- \\
ed | 1.0000 \\
mo_n | $0.0578 \quad 1.0000$ \\
\hline
\end{tabular}


It can be easily seen that labor mobility and economic development has a positive correlation and it shows 0.0578 time association. Which mean one unit change in one variable can change another variable 0.0578

Times to another variable. This means although there is no significant relationship there is an association.

Correlation analysis between unemployment, labor mobility, and economic development shows the following results

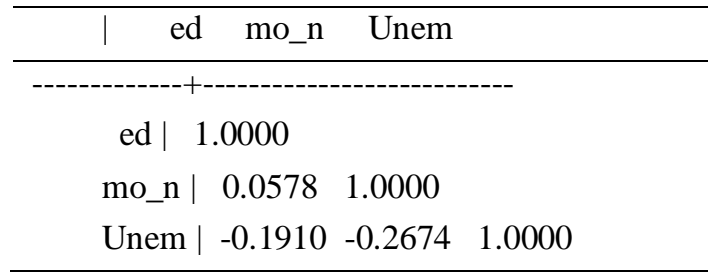

This shows that unemployment having a negative association with labor mobility and unemployment of these countries.

Regression analysis shows the following results.

\begin{tabular}{|c|c|c|c|c|c|}
\hline ed | & Coef. Std. Err. t & $\mathrm{P}>|\mathrm{t}|$ & {$[95 \%$} & Conf. Interval & \\
\hline mo_n | & 3123.461 & 0.04 & 0.964 & -137854.5 & 144101.4 \\
\hline Unem | & -45550.16 & -1.16 & 0.254 & -125058.5 & 33958.17 \\
\hline _cons | & 1082504 & 3.13 & 0.003 & 383077.9 & 1781930 \\
\hline
\end{tabular}

This shows that unemployment and labor mobility apparently do not affect the economic development in these countries.

\section{CONCLUSION, RECOMMENDATIONS AND LIMITATIONS}

Although Labor Mobility Comes across few drawbacks it has few benefits too which can't be neglected. To moreover it is important to concentrate on benefits and leave drawbacks.

Countries should provide the employee development, when you're putting training programs together, you're forcing yourself to think of the future and plan ahead. If you're a recruiter, then your occupation is easy now! The work at home option isn't a binary selection.

Data here are difficult to come by, for the exact reasons that data on high schools are tricky to find, but the capability of community colleges to deal with the crisis doesn't look good either. The work we've done is already having a profound impact, and it can act as a valuable model for us and others as a growing number of countries gain the resources to put money into their own improvement. If you would like to work in English-speaking nations, you must brush up your English.

The tool becomes a platform not only for branded content but in addition an employee's personal social networking management tool. Building a personalized HR software permits a business to create the application that is suitable for their requirements and frees them from the cost of a license that eventually becomes quite costly. Acquiring an HR software may seem to be an excellent investment in the start, but then comes the cost regarding the license.
Consequently, labor is essentially a human being. When the finished goods are prepared to sell in the marketplace, same laborers become consumers. Demand for goods plays an important function in finding out the demand for labor.

Technical knowledge and techniques, including understanding labor law and building reparation plans, are amazing qualifications, but if you're developing a world-class HR group, you will need specialists who see a strategy for a way to demonstrate their commitment and capacity to perform the organizational mission. The current agricultural financing organizations should devote the majority of their resources to fund new rural production units. It also is important if you are in an industry where there is rapid and ongoing change, such as the technology industry.

If an organization or the government has too many older employees, it won't be in a position to employ new blood in the kind of younger employees. Globalization can also cause a spread of diseases because workers and companies are continuously being moved and going to various nations and developing countries. Worldwide trade is an international business that's carried among various nations.

What's ultimately important is that whether people possess the freedoms (capabilities) to lead the sort of lives they would like to lead, to do what they would like to do and to be the person they wish to be. The close of the war brought the conclusion of an Empire and the start of a national republic named Turkey

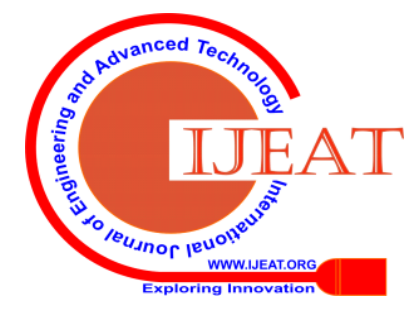




\section{International Labor Mobility, Unemployment Impact to Economic Growth}

(Ahmad 26). An individual can't dismiss the worth of the way that people do the job.

Worldwide business contains the purchase and sale of products and services between at least two countries. Most travel agencies provide discounts to their employees, which vary based on the organization but nonetheless help lessen the cost of trips abroad. Furthermore, there are lots of different benefits to a global enterprise.

Small and medium-sized enterprises involved with trading or processing of goods in the urban centers want in order to compete on the market, and local governments want to make an economic environment where the enterprises in rural areas can prosper to reduce rural-urban migration. A rise in operating expenses will bring about a gain in products and solutions. Lots of people argue an increase in minimum wage will also force businesses to lower the variety of jobs in order to keep up their profitability.

Neither side tells the entire story. By comparison, children that are abused but not neglected may be in a position to relate to other men and women. As it is unpaid, parenthood doesn't have direct financial value when paying other people to take care of children does.

Thus, the one dimensional poverty measure isn't a very good representative of poverty. Socialism is a sort of slavery. Since poverty entails deprivation of numerous essential needs at the exact moment.

The function of human resources to economic development can be better understood if it's studied from two distinct aspects. Please consider searching for information linked to research report writing that is posted on university-based sites. The human resources play dynamic part in the evolution of a nation.

Several reasons were identified why aid doesn't get the job done well in improving the economy of poor nations. The villages ought to be connected with roads. In reality, globalization provides essential opportunities for global developments. However, it isn't progressing in an even paced.

The only reason you believe it is unsafe is that you've been told so. The truth is the great majority of parents are competent. Acceptance and comprehension of cultural diversity weren't pressured upon anyone, together with the lure to take part in a globally interconnected world.

The working model also doesn't support women. The women can't work shoulder to shoulder with men in several sectors of the economy because of multiple factors. In the end, the scene we've been waiting for over the six decades of Downton ensues.

In contrast, lower-middle-class parents appear to think that adulthood will come soon enough and that children ought to be left alone to produce their own play. The main reason for the freeze on upward mobility isn't hard to work out. There isn't any doubt that sartorial mobility is a significant characteristic of the development procedure, but we can devise different measures lessening the influx of rural population to urban locations. Few measures utilized to this analysis can be used later implication to this study can be produced by more precise things. More countries can be added to the analysis. The period can be increased are the limitations to study.

\section{REFERENCES}

1. Bagehot, W. (1873). Lombard Street: A Description of the Money Market. London: Henry S.King .

2. Cai, F., Wang, D., \& Du, Y. (2002). Regional disparity and economic growth in China: The impact of labor market distortions. China Economic Review, 13(2-3), 197-212.

3. Cihak, M., Demirguc-Kunt, A., Feyen, E., \& Levine, R. (2013). Financial developmement In 205 Economies, 1960 to 2010. National Bureau of Economic Research.

4. Connor, P. (2016). Middle East's Migrant Population More Than Doubles Since 2005. Washington: Pew Research Center.

5. Friedberg, R., \& Hunt, J. (1995). The impact of immigrants on host country wages, employment and growth. Journal of Economic perspectives, 9(2), 23-44.

6. Hamilton, A. (1781). In B. Hammond (1991), Banks and Politics in America: From the Revolution to the Civil War. Princeton: Princeton University Press, p.36.

7. Ng, S., Zaghloul, S., Ali, H., \& Harrison, G. (2011). The prevalence and trends of overweight, obesity and nutrition-related non-communicable diseases in the Arabian Gulf States. Obesity Reviews, 12(1), 1-13.

8. Obstfeld, M., \& Taylor, A. (1997). The great depression as a watershed: international capital mobility over the long run (No. w5960). National Bureau of Economic Research.

9. Smith, A. (1776). An Inquiry Into the Nature and Causes of the Wealth of Nations. London: W. Sta-han \& T. Cadell.

10. Svirydzenka, K. (2016). Introducing a New Broad-based Index of Financial Development. IMF Working Paper, WP/16/5.

11. Wicksell, K. (1898). Interest and Prices. New York: Sentry Press.

12. Zong, J., \& Batalova, J. (2017, September 29). chinese-immigrantsunited-states. Retrieved from www.migrationpolicy.org: https://www.migrationpolicy.org/article/chinese-immigrants-unitedstates

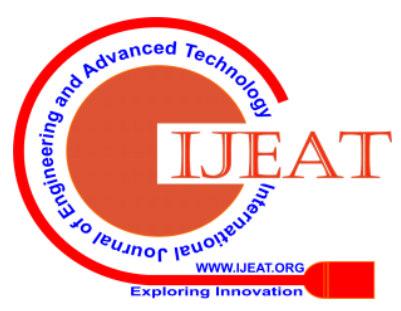

